\title{
FAULT DETECTION AND DIAGNOSIS FOR CONTINUOUS STIRRED TANK REACTOR USING NEURAL NETWORK
}

\author{
Ribhan Zafira Abdul Rahman*, Azura Che Soh, Noor Fadzlina binti Muhammad \\ Department of Electrical and Electronics, Faculty of Engineering, Universiti Putra \\ Malaysia, 43400 Serdang, Selangor, Malaysia \\ *Corresponding Author: ribhan@eng.upm.edu.my \\ Received 14 July, 2009; Revised 10 March, 2010
}

\begin{abstract}
The paper focuses on the application of neural network techniques in fault detection and diagnosis. The objective of this paper is to detect and diagnose the faults to a continuous stirred tank reactor (CSTR). Fault detection is performed by using the error signals, where when error signal is zero or nearly zero, the system is in normal condition, and when the fault occurs, error signals should distinctively diverge from zero. The fault diagnosis is performed by identifying the amplitude error of the CSTR output error.
\end{abstract}

Keywords Fault Detection and Diagnosis, Neural Network, CSTR

\section{INTRODUCTION}

Associated with an increasing demand for high performance as well as for more safety and reliability of dynamic systems, and a natural trend toward system automation, fault detection and diagnosis is becoming a strategic necessity as a result of increasing economic and environmental demands.

A fault can be defined as an unexpected change of the system functionality which may be related to a failure in a physical component or in a system functionality which may be related to a failure in a physical component or in a system sensor or actuator.

In recent years, a neural networks (NN) has been widely apply in the field chemical engineering, in process control, and as a powerful tool of function approximation and pattern recognition ${ }^{1}$. NN also were studied and applied to fault detection and diagnosis problem. NN have been used either predictor or dynamic models for fault diagnosis the fault diagnosis and pattern classifiers for fault identification.

In this paper, $\mathrm{NN}$ is used as a method for fault detection and diagnosis and then the method is applied to CSTR system. One of the researchers was using Support Vector Machines (SVM) in unsteady fault diagnosis for CSTR system ${ }^{2}$. Another researcher was using on-line approximator in process fault and diagnosis to CSTR system ${ }^{3}$. Meanwhile, J. B. Gomm and D. William, using on-line learning in neural network for fault diagnosis and applied to CSTR process ${ }^{4}$ and J. Zhang and A.J. Morris were using fuzzy neural networks method for on-line process fault diagnosis 5 . 


\section{ARTIFIAL NEURAL NETWORKS}

Artificial Neural Network (ANN) is the term used to describe a computer model assumption of the biological brain. It is a system loosely modeled on the human brain. It consists of a set of interconnected simple processing unit which combine to output a signal to solve a certain problem based on the input signal it received. The interconnected simple processing unit has adjustable gains that are slowly adjusted through iterations influenced by the input-output patterns given to the ANN.

An ANN is an information processing paradigm that inspired by the way biological nervous systems, such as the brain, process information. ANN is a system that has certain performance characteristics in common with biological neural networks. Basically, it is a system that handles many input signals, process them, and output them to solve a task that it has been trained to solve.

In this paper, feedforward network with multilayer perceptron (MLP) is used. A multilayer perceptron is shown in Figure 1. It is a net with one or more layers of node (also called hidden units) between the input units and output units. Feedforward ANNs allow signals to travel one way only; from input to output. There is no feedback (loops), example; the output of any layer does not affect that same layer. Feedforward ANNs tend to be straight forward networks that associate inputs with outputs.

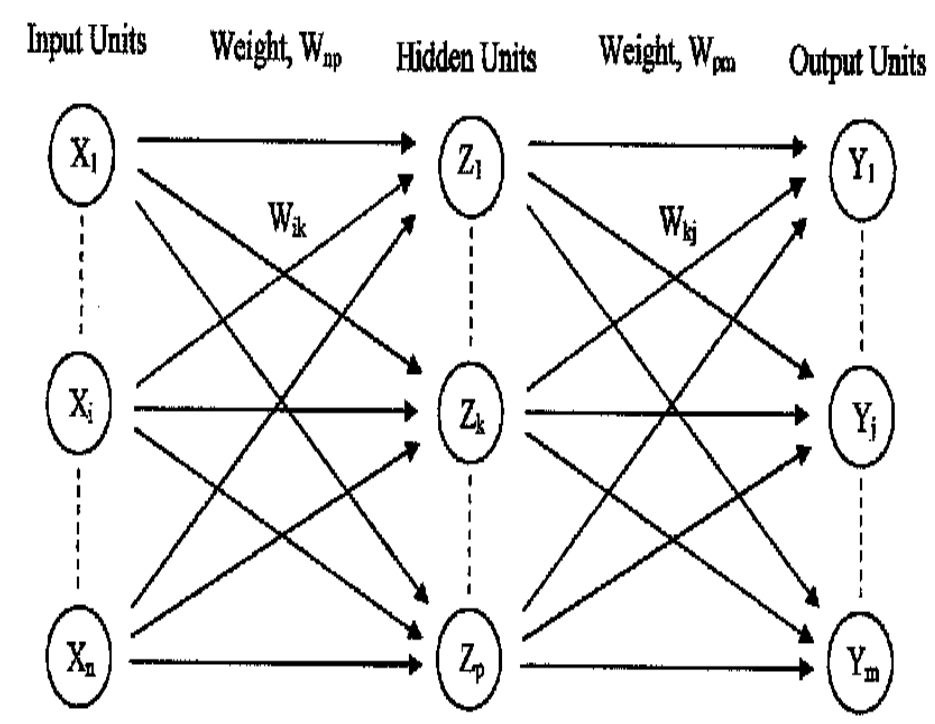

Figure 1: A multilayer neural network 


\section{THE PROCESS}

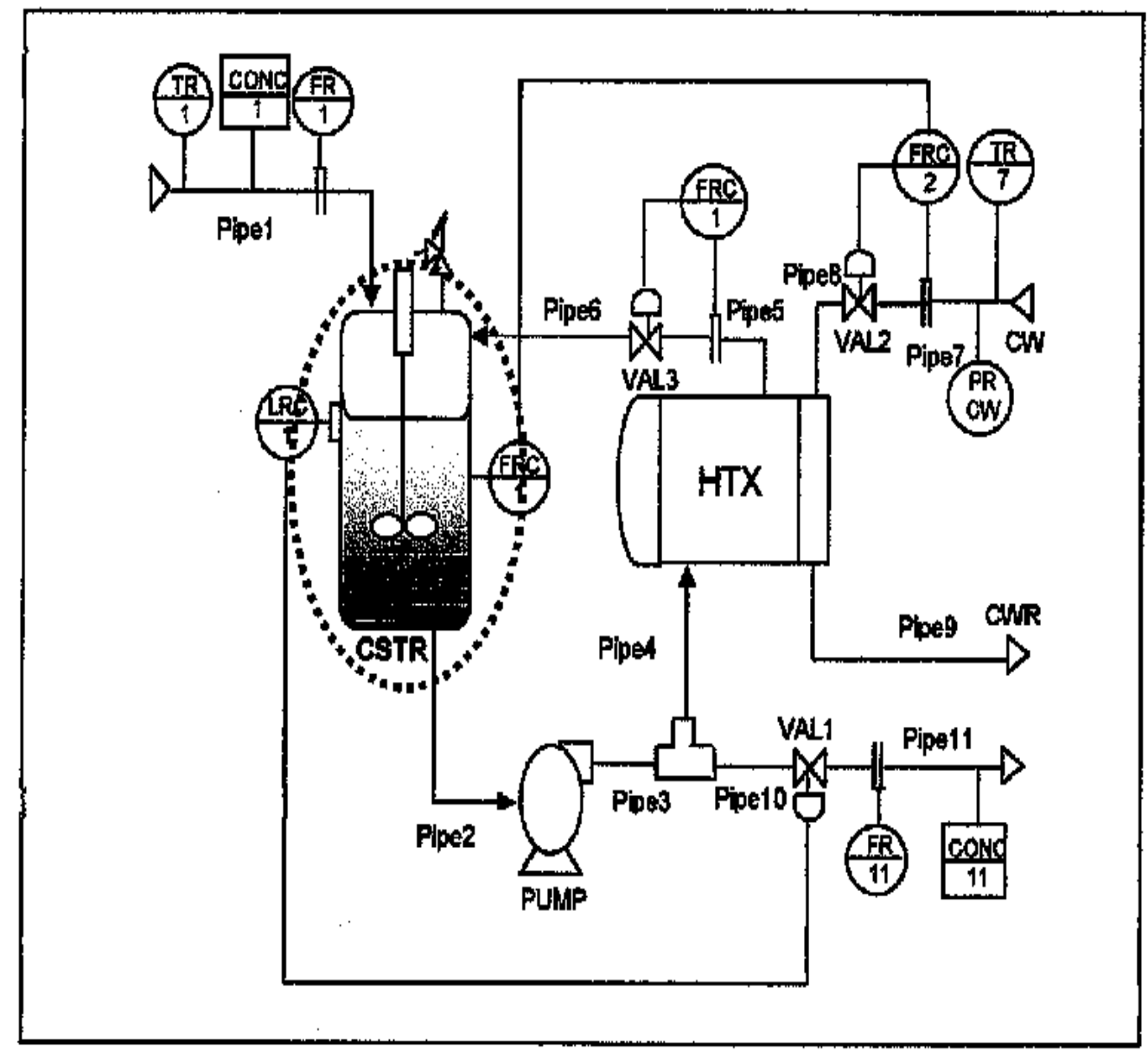

Figure 2: The Continuous Stirred Tank Reactor (CSTR) System

The Continuous Stirred Tank Reactor (CSTR) is one of the most common industrial vessels in a continuous process. It is widely used in the organic chemicals industry for medium and large scale production. Basically, it is a tank that mixes a continuous flow of inlet species. The species usually react to form a product within the tank at any time. Once the equipment is up and running, it is usually operated at steady state and designed to achieve well mixing.

The proposed fault diagnosis method has been applied to a simulated CSTR. A schematic diagram of the CSTR process is shown in Figure 2. An irreversible heterogeneous catalytic exothermic reaction from reactant $A$ to product $B(A \rightarrow B)$ takes place in the reactor vessel.

Generally, this paper is mainly divided into three major modules. The modules are:

1. The CSTR Model Design and Simulation

2. The Neural Network Training and Simulating 


\section{The Fault Detection and Diagnosis Module}

In order to design the CSTR model, the second order, exothermic, single irreversible reaction from reaction from reactant $\mathrm{A}$ to product $\mathrm{B}(\mathrm{A} \rightarrow \mathrm{B})$ is assumed to occur in the reactor. A schematic of the CSTR plant model that considered in this paper is shown in Figure 3. Table 1 shows the parameters of the plant or the nominal CSTR operating conditions. The reactor can be described by two nonlinear ordinary differential equations as shown in Equations 1 and 2. From the model equation, there is one manipulated variables and two controlled variables. The manipulated variables are coolant flow rate, $\mathrm{Q}$ and the controlled variables are concentration, $\mathrm{C}$ and temperature, $\mathrm{T}$.

$$
\begin{gathered}
\frac{d C(t)}{d t}=\frac{Q_{f}}{V}\left(C_{f}-C(t)\right)-K_{0} C(t) \exp \left[\frac{-E}{R T(t)}\right] \\
\frac{d T(t)}{d t}=\frac{Q_{f}}{V}\left(T_{f}-T(t)\right)-K_{1} C(t) \exp \left[\frac{-E}{R T(t)}\right]+K_{2} Q(t)\left[1-\exp \left(\frac{-K_{3}}{Q(t)}\right)\right]\left(T_{c f}-T(t)\right)
\end{gathered}
$$

Where

$$
\begin{gathered}
K_{1}=\frac{-\Delta H K_{0}}{\rho C_{p}} \\
K_{2}=\frac{\rho_{c} C_{p c}}{\rho C_{p} V} \\
K_{3}=\frac{h A}{\rho_{c} C_{p c}}
\end{gathered}
$$

The variable $\mathrm{C}$ and $\mathrm{T}$ are the concentration and temperature of the reactor, respectively. The coolant flow rate, $\mathrm{Q}$ is the control input. Within the tank reactor, two chemicals are mixed and react to produce a product compound $\mathrm{A}$ at a concentration $\mathrm{C}(\mathrm{t})$ with the temperature of the mixture being $\mathrm{T}(\mathrm{t})$. The reaction is both irreversible and exothermic. The control objective is to manipulate the coolant flow rate, $\mathrm{Q}(\mathrm{t})$ to control the effluent concentration $\mathrm{C}(\mathrm{t})$ at a desired value. 
Table 1: Parameters Value

\begin{tabular}{|c|c|c|}
\hline Parameter & Description & Nominal Value \\
\hline $\mathrm{Q}_{\mathrm{f}}$ & Feed flowrate & $100 \mathrm{~L} / \mathrm{min}$ \\
\hline $\mathrm{V}$ & Volume of reactor & $100 \mathrm{~L}$ \\
\hline $\mathrm{T}_{\mathrm{f}}$ & Feed temperature & $350 \mathrm{~K}$ \\
\hline $\mathrm{T}_{\mathrm{cf}}$ & Coolant temperature & $350 \mathrm{~K}$ \\
\hline $\mathrm{C}_{\mathrm{p}}, \mathrm{C}_{\mathrm{pc}}$ & Heat capacity & $0.239 \mathrm{~J} /(\mathrm{g} . \mathrm{K})$ \\
\hline$\rho, \rho_{\mathrm{c}}$ & Liquid density & $1000 \mathrm{~g} / \mathrm{L}$ \\
\hline $\mathrm{E} / \mathrm{R}$ & Activation energy & $1 \times 10^{4}$ \\
\hline $\mathrm{C}_{\mathrm{f}}$ & Concentration of feed & $1 \mathrm{~mol} / \mathrm{L}$ \\
\hline $\mathrm{K}_{0}$ & Velocity constant & $7.2 \times 10^{10} \mathrm{~min}^{-1}$ \\
\hline $\mathrm{K}_{1}$ & Constant & $1.44 \times 10^{13} \mathrm{KL} / \mathrm{min} / \mathrm{mol}$ \\
\hline $\mathrm{K}_{2}$ & Constant & $0.01 / \mathrm{L}$ \\
\hline $\mathrm{K}_{3}$ & Constant & $700 \mathrm{~L} / \mathrm{min}$ \\
\hline $\mathrm{hA}$ & Heat coefficient & $1.67 \times 10^{5} \mathrm{~J} /(\min . \mathrm{K})$ \\
\hline$\Delta \mathrm{H}$ & Heat of reaction & $-4.78 \times 10^{4} \mathrm{~J} / \mathrm{mol}$ \\
\hline
\end{tabular}

CSTR model is constructed in MATLAB Simulink Tool using equation (1) and (2). The CSTR is modeled by a non-linear system with one input and two outputs variables.

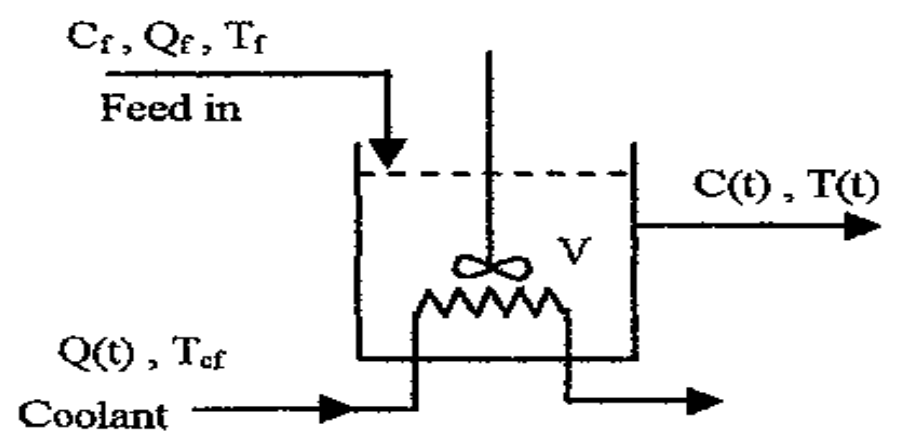

Figure 3: The CSTR plant model 


\section{EXPERIMENT}

In this paper, there are six several fault are considered as at Table 2. The system variable with deviation from steady state value in $10 \% \sim 20 \%$ is considered as light fault. The deviation above $20 \%$ is called heavy fault. The deviation $0 \% \sim 10 \%$ is permitted. In this paper, fault is created by increasing the variable value by $15 \%$ on the high side or decreasing the variable value by $15 \%$ on the low side. The percentage of $15 \%$ is chose because light fault is a normal fault that may occur in any control system situation.

Table 2: Fault Injection

\begin{tabular}{|l|l|l|}
\hline Fault Type & Fault injection & $\begin{array}{l}\% \\
\text { injection }\end{array}$ \\
\hline NF & None & None \\
\hline Fault 1 & Concentration of feed, $\mathrm{C}_{\mathrm{f}}$ is on the low side & $-15 \%$ \\
\hline Fault 2 & Concentration of feed, $\mathrm{C}_{\mathrm{f}}$ is on the high side & $+15 \%$ \\
\hline Fault 3 & Volume of reactor, V is on the low side & $-15 \%$ \\
\hline Fault 4 & Volume of reactor, V is on the high side & $+15 \%$ \\
\hline Fault 5 & Feed flowrate, $\mathrm{Q}_{\mathrm{f}}$ is on the low side & $-15 \%$ \\
\hline Fault 6 & Feed flowrate, $\mathrm{Q}_{\mathrm{f}}$ is on the high side & $+15 \%$ \\
\hline
\end{tabular}

ANN is used to model the CSTR system and all the Fault Model involve in this paper. There are three layers with seven neurons, contains an input neuron, five hidden neurons and two output neurons.

\section{RESULTS}

There are two variables of output errors, i.e error of $\mathrm{T}$ and error of $\mathrm{C}$ that will be plotted individually versus time. The errors for normal condition and faulty condition are shown in Figure 4 and Figure 5. The non fault errors that occurred are approximately zero in the CSTR model. The unknown data has been generated in the first module. The errors for both output models are shown in Figure 6 and Figure 7.

The figures of unknown data are used to compare with the database plot to verify the condition of these unknown data. From the graph, the error of unknown data for both outputs $\mathrm{T}$ and $\mathrm{C}$ are similar with Fault 1, as shown in Figure 4 and Figure 5. 


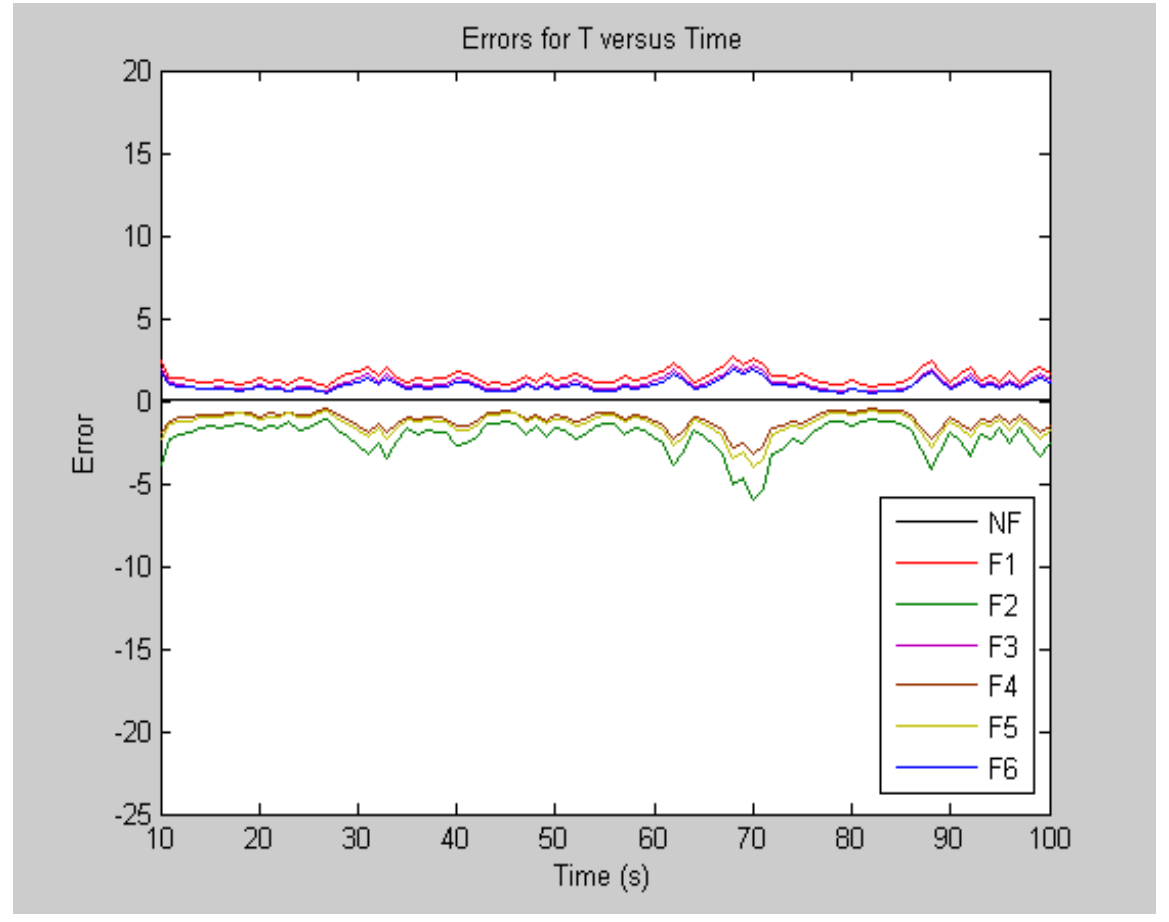

Figure 4: Errors for output T versus Time

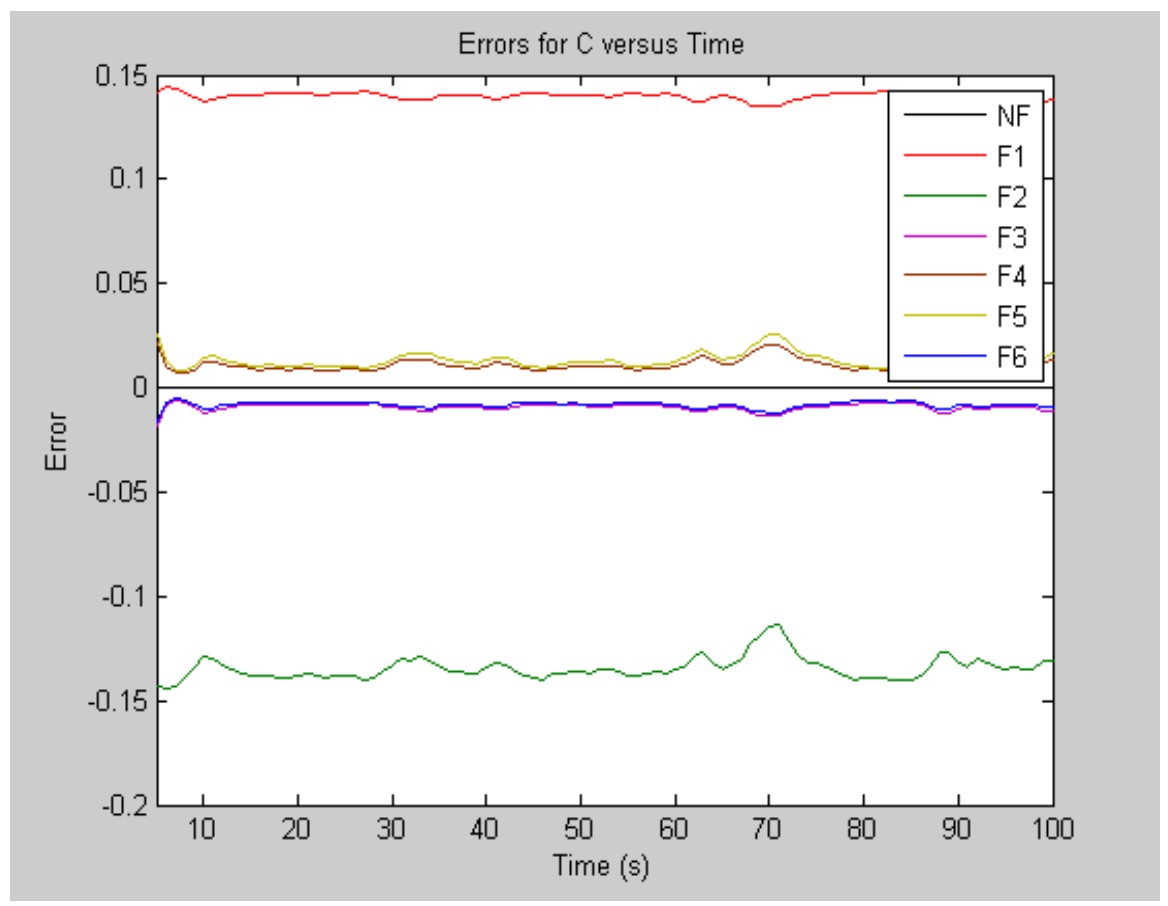

Figure 5: Errors for output $\mathrm{C}$ versus Time 
KATHMANDU UNIVERSITY JOURNAL OF SCIENCE, ENGINEERING AND TECHNOLOGY

VOL. 6, No. II, NOVEMBER, 2010, pp 66-74

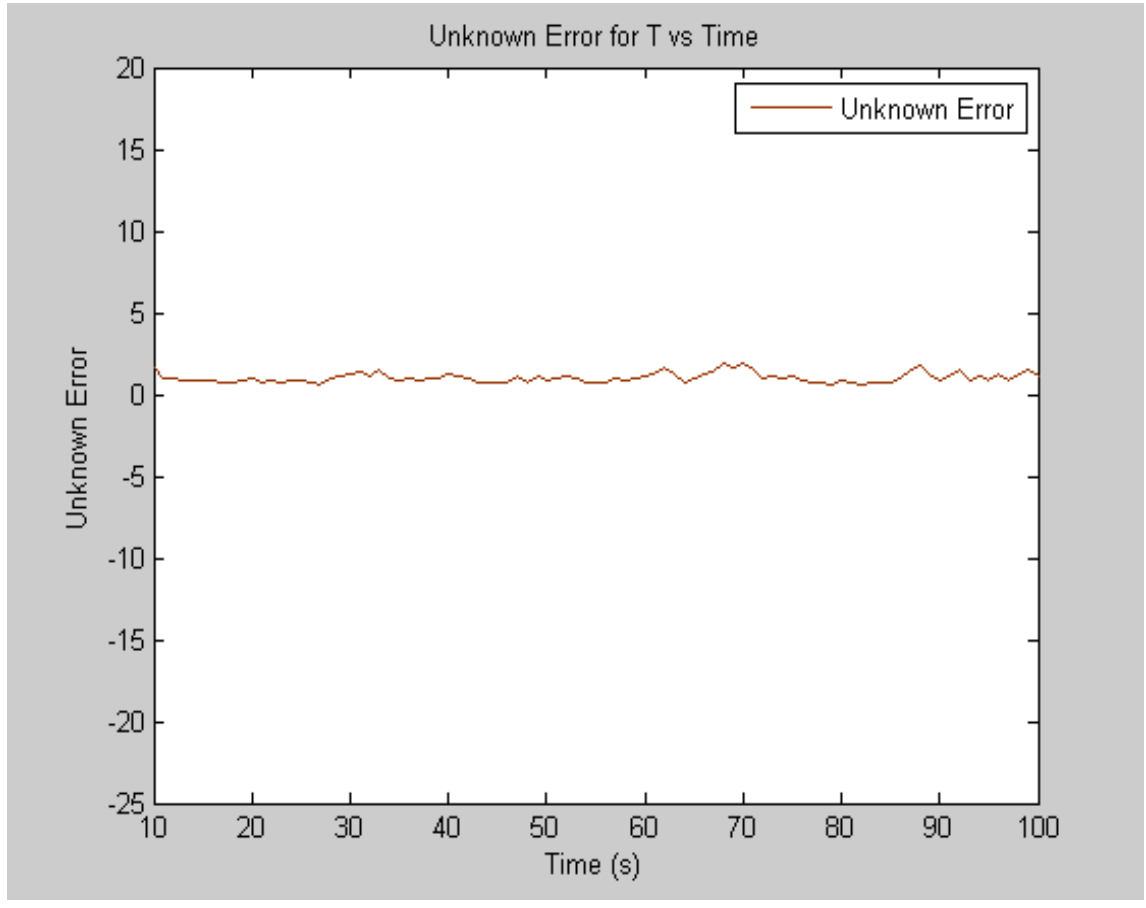

Figure 6: Error of unknown data for output $\mathrm{T}$

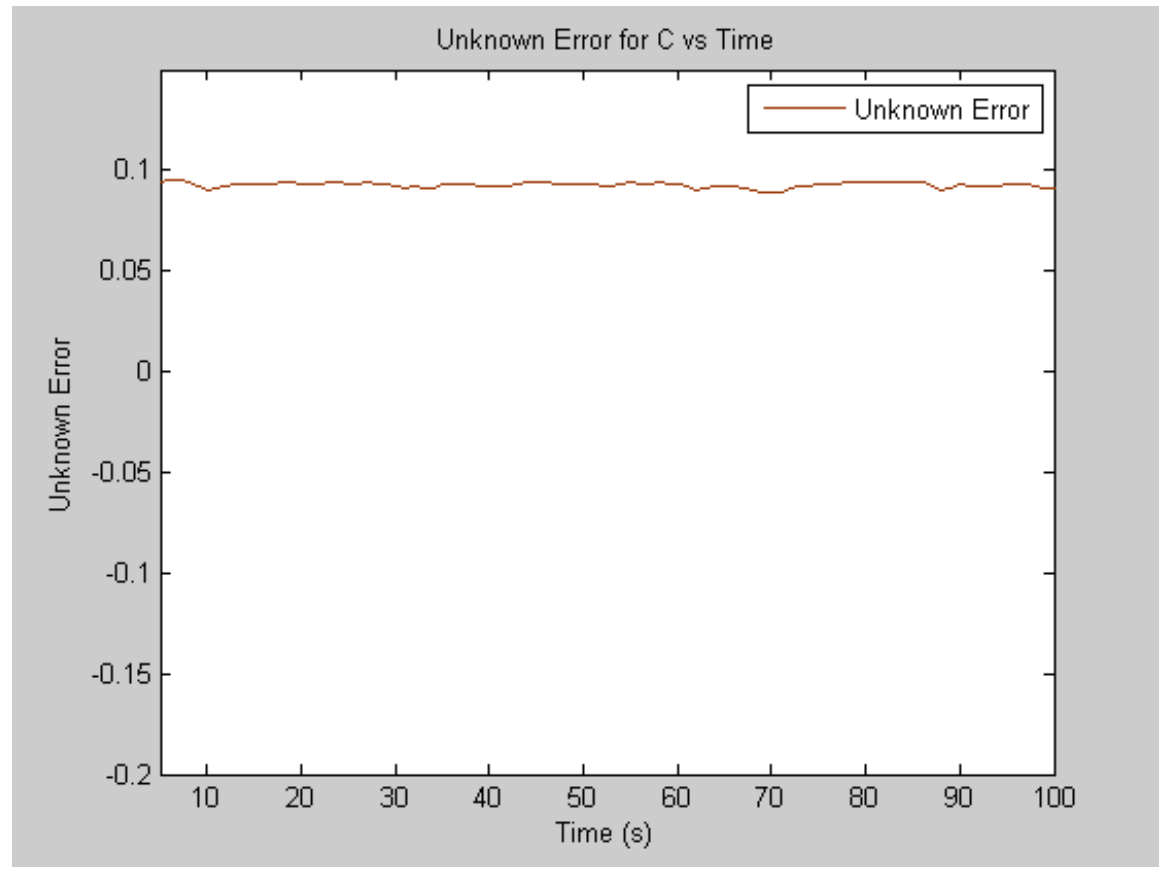

Figure 7: Error of unknown data for output C 


\section{CONCLUSION}

The CSTR model had been successfully developed using SIMULINK Tools and the neural network model had been created using Neural Network Toolbox. Feed forward backpropagation is a multilayer neural network which can successfully detect and diagnose the faults that implemented in this paper.

In normal condition, the errors for both CSTR outputs, $\mathrm{T}$ and $\mathrm{C}$ are approximately zero. Whereas, when the model is operating in faulty condition, the errors of the CSTR outputs are non-zero. The fault diagnosis is performed by identifying the error of the output errors of $\mathrm{T}$ and C. By comparing with the graph and database, the fault can be detected and diagnosis.

\section{REFERENCES}

1. Shui Y, Fan-yuan M, Jian-xue C, Xing-guo Y, \& Hong-bo S. 2002. Unsteady Fault Diagnosis Method for Chemical Process Based on SVM, Machine Learning and Cybernetics, Proceedings, 2002 International Conference, 2, 772-775. ISBN: 0-78037508-4

2. Sawattanakit N \& Jaovisidha V 1998. Process Fault Detection and Diagnosis in CSTR System using On-line Approximator, The 1998 IEEE Asia-Pacific Conference on Circuits and Systems, IEEE APCCAS, 747-750.

3. Gomm J.B \& Williams D. 1995. An Adaptive Neural Network for On-line Learning and Diagnosis of Process Faults, IEE Colloquium on Qualitative and Quantitative Modelling Methods for Fault Diagnosis, 9/1-9/5.

4. Zhang J. \& Morris A.J. 1994. On-line Process Fault Diagnosis using Fuzzy Neural Networks, Intelligent Systems Engineering, 3, 37-47. ISSN: 0963-9640 